\title{
Assessing the Relationship between Emotional Intelligence, Job Satisfaction and Organizational Learning Capability in Private Higher Educational Institutions in Egypt and India: A Comparative Study
}

\author{
Tarek A. El Badawy ${ }^{1}$, Shalini Srivastava ${ }^{2} \&$ Mariam B. Sadek ${ }^{1}$ \\ ${ }^{1}$ Department of Management and Organization, Faculty of Management Technology, German University in Cairo, \\ Cairo, Egypt \\ 2 Jaipuria Institute of Management, NCR Delhi, India \\ Correspondence: Dr. Tarek A. El Badawy, Assistant Professor of Management, Department of Management and \\ Organization, Faculty of Management Technology, German University in Cairo, Cairo, Egypt. E-mail: \\ tarek.el-badawy@guc.edu.eg
}

Received: October 26, 2014

Accepted: November 6, 2014

Online Published: November 16, 2014

doi:10.5430/ijba.v5n6p38

URL: http://dx.doi.org/10.5430/ijba.v5n6p38

\begin{abstract}
The purpose of this paper is to make a comparative study between Egypt and India aiming to measure the impact of three variables, which are: Emotional Intelligence (EI), Job Satisfaction (JS) and Organizational Learning Capability (OLC) among academicians in private Higher Educational Institutions (HEIs) in both countries Egypt and India. Data was collected from private HEIs in Egypt and India. The study employs standardized scales for Emotional Intelligence, Organizational Learning Capability and Job satisfaction variables. Sample consists of 100 faculty members from Egypt, and 100 faculty members from India. Various standard statistical tools such as Karl Pearson coefficient of correlation, $t$-test and regression analysis were used to interpret the data. The findings of this paper were interesting. It was found that the relationship between Emotional Intelligence and Job Satisfaction was non-significant, however, the relationship between the Organizational Learning Capability and the Job Satisfaction was found to be significant, with regards to both countries, Egypt and India. It was also found that there is a non-significant relationship between OLC and EI in India but a significant one between OLC and EI in Egypt. Another main finding is that the OLC, in Egypt, when found to be high, the relation between EI-JS was found to be positive and almost significant. However, when having low level of OLC, the EI-JS relationship was found to be inverse and non-significant. For the limitations and implications; it is due to certain features of the sample and the use of measurement scales, that the final results should be considered with caution. Further research in other contexts using qualitative methods is needed to validate the findings. To make it more practical, it could be concluded that seeking to develop the employees in the workplace is found to be of a great importance, since that the organizational learning capability was found to be related to the Job Satisfaction and positively affecting it. For the originality of this paper, it is worth to mention that this paper is considered as the first comparative study between Egypt and India in the topic of Emotional Intelligence and Job Satisfaction.
\end{abstract}

Keywords: emotional intelligence, job satisfaction, organizational learning capability, academicians, private higher educational institutions, Egypt, India

\section{Introduction}

To keep pace with the rapid change in globalization, it's pertinent for the academic institutions to constantly update their faculty in learning and development aspects. In order to be competitive and efficient, it's crucial for the academicians to have an expertise in one's domain which can further lead to satisfaction. It's vital for the organization to understand various facets that lead to organizational learning and job satisfaction. In order to be a win-win situation, transparency from faculty and management is important.

This paper is aiming to provide a collaborative study between both countries, Egypt and India with the purpose of measuring the impact of three variables, which are Emotional Intelligence, Job Satisfaction and Organizational Learning Capability among academicians in Private Higher Educational Institutions in Egypt and India. The concept of OLC was not discussed thoroughly by many researchers; but mainly by Alegre and Chiva (2008). 
The main reason to make this comparative study between Egypt and India is due to the fact that the collaborative and comparative studies that has been made between the 2 countries are considered to be very few and in very limited fields like in religion, politics and some other fields; even fewer researches have been made in the field of Management between Egypt and India. No researches or Comparative Studies between Egypt and India were found to be existing in the area of Emotional Intelligence, and that's why this paper was aiming mainly to study the concept of Emotional Intelligence along with 2 other variables, which are Job Satisfaction and Organizational Learning Capability and their impact among Academicians in Higher Private Educational Institutions in both countries.

\section{Emotional Intelligence, Job Satisfaction and Organizational Learning Capability}

\subsection{Emotional Intelligence (EI)}

Beginning with the definition of Emotional Intelligence (EI), Dincer and Orhan (620) have provided that there are four models that define in different ways the concept of EI. The four models are named after their researchers who have attempted to define EI. The researchers are Mayer \& Salovey, Bar-on, Goleman, and Wong \& Law. Each and every researcher of those four groups defines EI in a different way. It is important to mention that the models are not shown in order of appearance, which means that any of the four models can come at first or at last. Starting with Mayer and Salovey, and who were considered as the first ones to use the term of "Emotional Intelligence"; defined it as an ability to understand one's own feelings as well as others. The second model was defined by Bar-on which relates EI in coping successfully with the demands from the outer world (Dincer and Orhan). EI is considered as being one of the most important topics that have been introduced to psychology and management in the last ten years (Ameli, Lari and Shooshtarian 2013: 28). In a general sense, EI refers to the individual's abilities to regulate emotions and recognize them in ourselves and in the others as well (Alegre and Chiva 2008: 680). This relatively new concept of EI has received high levels of interest and attention in a variety of literature bases, for example competency management. Therefore, the concept itself might be considered as a group of individual competencies that are critical for organizational performance (Alegre and Chiva 2008: 681).

Goleman, who is considered as one of the most prominent researchers in the field of EI, has been suggesting that EI is made of four components and which are self-awareness, self-management, social awareness and social management (Alam 2009: 126). Jamali, Sidani and Abu-Zaki are also three researchers who have been investigating empirically the variations existing in EI competency scores. This applies in a sample made of employees and managers measuring the levels of self-awareness, self-regulation, self-motivation, social awareness and finally the social skills. The results of the investigation were suggesting the presence of differences in EI competency scores across the various EI competencies for both males and females. The males were getting higher scores on both self-regulation and self-motivation, while the females were achieving higher scores on self-awareness, empathy and social skills as well. It has also been proven that EI levels are significantly increasing with the managerial position (Ameli, Lari and Shooshtarian 2013: 31). Alegre and Chiva (2008: 682) wrote in their paper that the construct of EI could be described by its four components, which are: self-awareness of emotions, social awareness and which is also described as the awareness of the emotions in others, management of emotions in self, and finally the management of emotions in others. Dincer and Orhan (632) wrote in their findings that the employees should assure having the EI competency factors, which are self-awareness, self-management, motivation, empathy and social skills and which could be interpreted in other words by saying that the employees should not only evaluate, use and regulate effectively their emotions, they are also requested to understand and to evaluate the emotions of others.

\subsection{Job Satisfaction (JS)}

Alam (2009: 124) mentioned, in his paper, the importance of job satisfaction (JS). He said that JS received a great deal of attention from researchers in the field of organizational behavior and that employees might change their jobs several times due to many reasons, but JS remains an important topic that requires scientific investigation. Ameli, Lari and Shooshtarian (2013:29) add to the importance of understanding JS by saying that JS depends mainly on the balance between work-role inputs and work-role outputs and that employees compare between their inputs and their outputs, and if the outputs are relatively higher than the inputs, job satisfaction will be increased. Workplace passion has also being linked with JS in the comparative study between public and private sector managers in India (Srivastava, 2012). Alegre and Chiva (2008: 683) also add to the point of the importance of understanding JS by saying that JS can lead to behaviors by the employees that can influence the organizational functioning and importance.

It is also important to define the concept of JS; this term could be defined as the individual's attitude shown towards his or her job. JS is also based on the individual's experience and which is related to the individual's needs, expectations and to the benefits achieved from his/her job (Alam 2009: 127-128). Another way to define JS is saying 
that it is simply how the individuals feel in concern with the various aspects of their jobs. It also extends to what is liked or what is disliked by people about their jobs (Ameli, Lari and Shooshtarian 2013: 29). Alegre and Chiva (2008: 683) defined JS as the employee's affective reactions to his or her job and this reaction is based mainly on a comparison between the actual outcomes and the desired ones. It is also the degree to which individuals like their jobs. At last, Krishnakumar (2008: 8) also defines JS as the multidimensional psychological responses to the individual's job and that it is made out of three components: the cognitive (or the evaluative) and which is mainly formed by the evaluations made by the individual concerning his or her job characteristics and concerning the job environment as well, this evaluation is made by using some "standard" or "frame of reference". The second component is the affective or the emotional component and which is consisting of the overall feelings, pleasant or unpleasant, that the individual could have towards the job itself and by being accumulated over time. The third and last component is the behavioral one and which includes the specific behaviors and intentions that occur as an outcome of the formation of a certain attitude. All those three components summed together, result in forming and in the functioning as well of a job attitude. JS is also influenced by several factors such as the organizational factors, the environmental factors, the nature of the job, and the characteristics of the employee (Ameli, Lari and Shooshtarian 2013: 31).

\subsection{The Organizational Learning Capability $(O L C)$}

With the rapid change in global market in terms of innovations, august manpower, the Organizational Learning Capability is much talked about amongst academicians and managers. Alegre and Chiva (2008: 681) said that the concept of Organizational Learning has been expanding over the last years and especially among practitioners and in the field of research as well. There are many reasons for this expansion and the growth in importance. One of the main reasons is the appearance of new characteristics for the business environment. OLC, as a concept, is stressing on the importance of the facilitating factors for the organizational learning. In order to define, with more details this concept, a thorough look into the definition presented by Goh and Richards, shall take place. Goh and Richards define OLC as the managerial and organizational characteristics that help in facilitating the organizational learning or that allow an organization to learn.

OLC, as a concept is made of five facilitating factors. Experimentation, the first facilitator, is defined as the level to which the new suggestions and ideas are presented, attended to and dealt with in a sympathetic way. In the Organization Learning literature, experimentation is a dimension that is strongly supported and it requires to try out new ideas, to be curious about how different things work, and to carry out or bring about changes in the work processes. Risk taking, the second facilitator, is defined as the tolerance for the errors, uncertainty and ambiguity. It is worthy also to mention, with regard to the risk taking, that failure is considered as a necessary requirement for an effective Organizational Learning. Interaction with the external environment, the third facilitator, is defined as the extent or the scope of relationships existing with the external environment. The factors that are beyond the direct control or influence of an organization are all forming the external environment. Dialogue, the fourth facilitator, is crucially important for the Organizational Learning and it is defined as a sustained collective inquiry into the certainties, assumptions, and processes that create everyday experience. Dialogue is also thought to create meaning and comprehension since it generates individual learning and organizational learning as well. Participative decision-making, the last and fifth facilitator, is referring to the degree of influence exercised by the employees in the process of decision-making. Different organizations use the participative decision-making to have a benefit from the effects of such a process, which is reflected in a high employee involvement, organizational commitment and job satisfaction.

\section{The Research Gap}

Since HEIs deal primarily with the acquisition and provision of knowledge, investigating the concepts of emotional intelligence, organizational learning capabilities and job satisfaction becomes valuable guidelines towards improving knowledge management, and understanding how these concepts are administered differently in different cultures among academicians. There is a gap in the research in the field of EI and especially with concern to the relation between EI and JS on the level of academicians in higher educational institutions. Whether private or public sectors, the relationship is also studied on a very limited scope and in some specific countries, where not all cultures are presented. It is also highly recommended to go deeper with the concept of OLC and how it could be linked to the EI and JS.

\section{Hypotheses Development}

As the main objective of this paper is to study the three main variables of EI, JS and OLC in Egypt and India and to study if there is a relationship between them, the following hypotheses are formulated to be studied in this paper. 


\section{Hypotheses:}

H01: EI has equal mean levels in Egypt and India

H02: JS has equal mean levels in Egypt and India

H03: OLC has equal mean levels in Egypt and India

H04: No significant relation between EI and JS in Egypt and India

H05: No significant relation between OLC and JS in Egypt and India

H06: No significant relation between OLC and EI in Egypt and India

\section{Method}

\subsection{Participants and Procedure}

Hypotheses were tested within the context of the Higher Education Industry in Egypt and India. Respondents were academicians in private HEIs in both countries; Data were obtained through a questionnaire developed by Joaqui'n Alegre and Ricardo Chiva. The reliability of the instrument was tested with a test-retest procedure. The task of personally delivering the questionnaire together with an explanatory cover letter was given to graduate students in Egypt and India. In Egypt the questionnaire was given to 160 randomly selected faculty members in four private universities in Cairo, Egypt. In India, the questionnaire was also given to 160 randomly selected faculty members belonging to 15 Management Institutions located in Delhi-NCR regions of India were the respondents are studying. The completed questionnaires were collected within three weeks after delivery, with 100 responses that were used in the data analysis for an overall return rate of $62.5 \%$.

\subsection{Scales Used}

In order to obtain data on the study variables, three standardized scales were used. Job Satisfaction was conceptualized as the dependent variable whereas Organizational Learning Capability and Emotional Intelligence as the independent variables. The measures used in this study were borrowed from their original source and adapted from Indian work setting.

Emotional Intelligence scale (EI): The researchers used the Schutte et al. (1998) EI scale, which is a self-report, Likert-type scale ranging from strongly agree to strongly disagree. The scale consisted of 33 items. The sum of all items constitutes the total scale score, which can range from 33 to 231 (higher scores indicate greater EI). The reliability of the scale was found to be 0.85 .

Organizational Learning Capability (OLC): For the present study, Chiva et al.'s (2007) OLC measurement instrument was used. The OLC measurement instrument was applied using a 7-point Likert-type scale, where 1 represented total disagreement and 7 represented total agreement .The total score is derived by adding the scores of all the items which ranges from 14 to 70 . The scale was validated by Chiva et al., through an employee based survey in ceramic industry. Cronbach $\alpha$ was found to be 0.88 .

Job Satisfaction Scale (JS): The scale comprised of five items. Items 1-2 taken from Brayfield \& Rothe (1951); Items 3-5 taken from Krishnakumar (2008). The items were measured on a five-point rating scale where 1 represented strongly disagree and 5 as strongly agree for items such as "I find real enjoyment in my work" and "I am fairly satisfied with my coworkers". The reliability of the scale was 0.64 .

\section{Methods of Analysis}

The analysis for the present study used SPSS, Version 17, (a product of IBM ${ }^{\circledR}$ ).

Descriptive statistics, Correlation \& Regression analysis and independent samples T-test were used to analyze the data.

Cronbach Alpha reliability coefficients are calculated for the 3 main variables; EI, JS and OLC in both countries; Egypt and India and the table shows it. All coefficients are accepted in both countries as shown in Table 1.

Table 1. Cronbach Alpha of the 3 variables showing the reliability of the study

\begin{tabular}{lll} 
& Egypt & India \\
\hline JS & 0.64 & 0.64 \\
\hline EI & 0.84 & 0.87 \\
\hline OLC & 0.79 & 0.67 \\
\hline
\end{tabular}

All coefficients are acceptable in both countries 


\section{Analysis}

7.1 Descriptive Statistics and Comparison of the 3 Basic Variables in Both Egypt and India

Table 2. EI, OLC and JS in both countries: Egypt and India

\begin{tabular}{|c|c|c|c|c|c|c|c|}
\hline & Country & $\mathrm{N}$ & Mean & Std. Deviation & $\mathrm{t}$ & P-value & \\
\hline \multirow[t]{2}{*}{ EI } & Egypt & 100 & 125.86 & 13.20 & \multirow{2}{*}{-1.32} & \multirow{2}{*}{0.187567} & \multirow{2}{*}{$\mathrm{P}>0.05$ Non-significant } \\
\hline & India & 100 & 128.15 & 11.21 & & & \\
\hline \multirow[t]{2}{*}{ OLC } & Egypt & 100 & 39.93 & 7.39 & \multirow{2}{*}{-16.44} & \multirow{2}{*}{0.000000} & \multirow{2}{*}{$\mathrm{P}<0.001$ Highly Significant } \\
\hline & India & 100 & 54.25 & 4.61 & & & \\
\hline \multirow[t]{2}{*}{ JS } & Egypt & 100 & 18.85 & 3.08 & \multirow{2}{*}{-1.49} & \multirow{2}{*}{0.138567} & \multirow{2}{*}{$\mathrm{P}>0.05$ Non-significant } \\
\hline & India & 100 & 19.45 & 2.61 & & & \\
\hline
\end{tabular}

\section{Fail to reject H01.}

\section{Fail to reject $\mathrm{H02}$.}

\section{Reject H03.}

EI and JS show very close results in both countries and no significant difference can be detected.

On the contrary, OLC has much higher mean in India compared to Egypt and the difference is highly statistically significant.

\subsection{Correlation and Regression Analysis}

Correlation matrix for the 3 variables in Egypt and India are shown in Table 3.

Table 3. The relationship among the 3 variables: EI, JS and OLC

\begin{tabular}{lllll} 
& \multicolumn{2}{l}{ Egypt $(\mathrm{N}=100)$} & \multicolumn{2}{l}{ India $(\mathrm{N}=100)$} \\
\cline { 2 - 5 } & EI & OLC & EI & OLC \\
\hline JS & 0.12 & $0.27^{* *}$ & 0.01 & $.38^{* *}$ \\
\hline EI & & $0.26^{* *}$ & & 0.04 \\
\hline
\end{tabular}

\section{Fail to reject $\mathrm{H04}$ in both countries.}

\section{Reject $\mathrm{HO5}$ in both countries.}

\section{Fail to reject $\mathrm{H06}$ in India.}

\section{Reject $\mathrm{H06}$ in Egypt.}

Correlation of EI with JS is nonsignificant ( $p>0.05$ ) in both countries and very weak almost zero in India.

Correlation of EI with OLC is highly significant in Egypt $(p<0.01)$ and very weak Non-significant relation in India.

Correlation of OLC with JS is highly Significant in both Countries but stronger in India.

JS is regressed on EI in both countries Egypt and India and the results are shown in Table 4.

Table 4. Regression of JS on EI

\begin{tabular}{|c|c|c|c|c|c|}
\hline & Adjusted R Square & $\begin{array}{l}\text { Standardized } \\
\text { Coefficients Beta }\end{array}$ & $\mathrm{t}$ & P-value & \\
\hline Egypt & 0.005 & .125 & 1.242 & .217 & $\mathrm{P}>0.05$ Non-significant \\
\hline India & -.010 & .012 & .117 & .907 & $\mathrm{P}>0.05$ Nonsignificant \\
\hline
\end{tabular}

The numbers are showing that there is a non-significant relation of JS and EI in both countries, Egypt and India.

The P-Value of Egypt is 0.217 ( $\mathrm{P}>0.05)$, which brings a relation that is non-significant between EI and JS.

Same applies for India, the P-Value of India is $0.907(\mathrm{P}>0.05)$ which is still a non-significant relation between EI and JS. 
JS is regressed on OLC in both countries Egypt and India and the results are shown in Table 5.

Table 5. Regression of JS on OLC

\begin{tabular}{lccccc}
\cline { 2 - 4 } & $\begin{array}{c}\text { Adjusted R } \\
\text { Square }\end{array}$ & $\begin{array}{c}\text { Standardized } \\
\text { Coefficients Beta }\end{array}$ & $\mathrm{t}$ & P-value \\
\hline Egypt & 0.066 & .275 & 2.827 & .006 & $\mathrm{P}<0.01$ Highly Significant \\
\hline India & .137 & .382 & 4.086 & .000 & $\mathrm{P}<0.001$ Highly Significant \\
\hline
\end{tabular}

The numbers are showing a highly Significant relation of JS and OLC in both countries, Egypt and India.

The P-Value of Egypt is $0.006(\mathrm{P}<0.01)$, which brings a highly significant relation between JS and OLC.

The $\mathrm{P}-$ Value of India is $0.000(\mathrm{P}<0.01)$, which also brings a highly significant relation between JS and OLC.

\subsection{Multiple Regression Analysis}

JS as a dependent variable is regressed on both EI and OLC in both countries Egypt and India and the results are shown in Table 6.

Table 6. Regression of JS on EI and OLC

$\begin{array}{cccc}\begin{array}{c}\text { Adjusted R } \\ \text { Square }\end{array} & \begin{array}{c}\text { Standardized } \\ \text { Coefficients Beta }\end{array} & \mathrm{T} & \text { P-value }\end{array}$

\begin{tabular}{lccccccc} 
& & OLC & EI & OLC & EI & OLC & EI \\
\hline Egypt & 0.059 & .260 & .055 & 2.57 & .546 & .012 & .587 \\
\hline \multirow{2}{*}{ India } & 0.128 & .382 & -0.004 & 4.063 & -0.042 & 0.0000 & .967 \\
\hline
\end{tabular}

EI is non-significant in Egypt $(\mathrm{P}>0.05)$ while OLC is significant $(\mathrm{P}<0.05)$ when both are introduced as independent variables

EI is non-significant in India $(\mathrm{P}>0.05)$ while OLC is highly significant $(\mathrm{P}<0.001)$ when both are introduced as independent variables

OLC for Egypt $(\mathrm{P}<0.05)$ is Significant and EI is Non-significant.

\subsection{Study of the Moderation Effect of OLC on EI-JS Relation}

A moderator variable can be considered when the relationship between a predictor variable and a dependent variable is strong, but most often it is considered when there is an unexpectedly weak or inconsistent relationship between a predictor and a dependent variable. The moderating effect is typically expressed as an interaction between predictor and moderator variable (Aldwin, 1994; Baron \& Kenny, 1986; Holmbeck, 1997).

In this study, the researcher hypothesizes that JS (the dependent variable or y) is predicted by EI (the independent variable or $\mathrm{x}$ ). When JS (y) is regressed on EI (x) there was only a weak insignificant relationship.

On the other hand, when JS is regressed on OLC there was a positive significant relation. Because the relationship between EI and JS had been expected to be significant, the researcher formulates a new hypothesis, namely that OLC moderates or enhances the effect of EI on JS. A third independent variable is, therefore, introduced, that is, the interaction term of EI * OLC. This new variable of interaction tests whether OLC is a moderator variable. When it is added to the regression analysis and found to have a significant relationship with JS, the moderator hypothesis is supported.

When introducing the interaction term one should be aware of the problem of multi-collinearity that may result when the variables being multiplied to generate the interaction term (EI X OLC) are highly correlated with each other. Multicollinearity causes "bouncing betas" in which the direction of the beta terms can shift from previously positive to negative relationships or vice versa (Cohen, 1978). Multi-collinearity may be reduced by centering continuous predictor and moderator variables. This is accomplished by subtracting the sample mean from respective variable, thereby obtaining a centered deviation score with a mean of zero. Centering the beta terms reduces the magnitude of the correlations between the independent variables, thus reducing multi-collinearity (Aldwin, 1994). 
The results of OLCcent, EIcent, Interaction OLCcent*EIcent is shown in Table 7.

Table 7. OLCcent, EIcent, interaction of OLCcent*EIcent

\begin{tabular}{lllll}
\hline $\begin{array}{l}\text { Adjusted } \\
\text { Square }\end{array}$ & $\mathrm{R}$ & $\begin{array}{l}\text { Standardized } \\
\text { Coefficients Beta }\end{array}$ & $\mathrm{T}$ & P-value \\
\end{tabular}

\begin{tabular}{|c|c|c|c|c|}
\hline \multirow{6}{*}{ Egypt } & \multirow{6}{*}{0.091} & OLC Centered & OLC Centered & OLC Centered \\
\hline & & 0.203 & 1.963 & 0.053 \\
\hline & & EI Centered & EI Centered & EI Centered \\
\hline & & 0.063 & 0.632 & 0.529 \\
\hline & & $\begin{array}{l}\text { EI Centered multiplied } \\
\text { by OLC Centered }\end{array}$ & $\begin{array}{l}\text { EI Centered multiplied by } \\
\text { OLC Centered }\end{array}$ & $\begin{array}{l}\text { EI Centered multiplied } \\
\text { by OLC Centered }\end{array}$ \\
\hline & & 0.208 & 2.092 & 0.039 \\
\hline \multirow{7}{*}{ India } & \multirow{7}{*}{0.124} & OLC Centered & OLC Centered & OLC Centered \\
\hline & & 0.391 & 4.12 & 0.000082 \\
\hline & & EI Centered & EI Centered & EI Centered \\
\hline & & 0.008 & 0.086 & 0.932 \\
\hline & & & & \\
\hline & & $\begin{array}{l}\text { EI Centered multiplied } \\
\text { by OLC Centered }\end{array}$ & $\begin{array}{l}\text { EI Centered multiplied by } \\
\text { OLC Centered }\end{array}$ & $\begin{array}{l}\text { EI Centered multiplied } \\
\text { by OLC Centered }\end{array}$ \\
\hline & & 0.071 & 0.731 & 0.466 \\
\hline
\end{tabular}

The result of Introducing the interaction term $\mathrm{OLC} * \mathbf{E I}$ in the multiple regression model:

In India, the interaction has no significant effect together with EI and the only significant independent variable is OLC.

In Egypt, the interaction of OLC with EI is Significant $(\mathrm{P}<0.05)$ and OLC became border line significant proving the moderation effect of OLC on the EI- JS relation.

7.5 Regression of JS on EI at Two Levels of OLC

To illustrate the moderation effect of OLC on EI-JS relation in Egypt, the Egyptian group is divided to two subgroups one with low OLC (less than the mean value) and the other group with high OLC (higher than the mean value). The relation of EI-JS is determined for each group alone. The results show completely different relation emphasizing the moderation role of OLC on the EI- JS relation in Egypt as it is clear from the following Table 8 and graphs. For low OLC, the EI-JS relation is inverse and nonsignificant ( $>0.05$ ); while for high OLC, the relation is positive and almost significant $(\mathrm{p}=0.097)$.

Table 8. Illustrating the moderating effect of OLC on EI- JS relation in Egypt

\begin{tabular}{lllll} 
& $\begin{array}{l}\text { Unstandardized } \\
\text { Coefficients }\end{array}$ & $\begin{array}{l}\text { Standardized } \\
\text { Coefficients }\end{array}$ & $\mathrm{T}$ & P-value \\
& $\mathrm{B}$ & Beta & & \\
\hline LOW OLC & -.031 & -.127 & -.780 & .441 \\
HIGH OLC & .051 & .214 & 1.685 & .097 \\
\hline
\end{tabular}


This case doesn't apply in India when we tried measuring the regression of JS on EI at two levels of OLC.

\begin{tabular}{llll}
\hline $\begin{array}{l}\text { Unstandardized } \\
\text { Coefficients }\end{array}$ & $\begin{array}{l}\text { Standardized } \\
\text { Coefficients }\end{array}$ & $T$ & P-value \\
& &
\end{tabular}

B Beta

\begin{tabular}{|c|c|c|c|c|c|}
\hline LOW OLC & -.007 & -.030 & -.213 & .832 & $\mathrm{P}>0.05$ Non-Significant \\
\hline HIGH OLC & .024 & .109 & .750 & .457 & $P>0.05$ Non-Significant \\
\hline
\end{tabular}

The results show completely non-significant relations of EI-JS at both levels of OLC.

However, a similar trend as for Egypt is that the relation is changed from being reverse at low OLC to positive in high OLC but both are weak and non-significant.

\section{Discussion}

Analysis of the results shows that the Emotional Intelligence has almost equal mean levels in India and Egypt which could be interpreted that EI levels in both India and Egypt are statistically significant with no statistically significant difference detected between both levels of EI in the two countries. Same applies for Job Satisfaction; there are almost equal mean levels of Job Satisfaction in Egypt and India. This could be interpreted as well that JS levels in both countries are statistically significant and that no statistically significant difference could also be detected between the two levels of JS in India and Egypt. For the third variable, OLC, it doesn't have even close mean levels in India and Egypt. It was found that OLC in India is much higher than OLC in Egypt, this could be interpreted that the levels of OLC in both countries are of a high statistical significance difference. Then, with regard to the three variables separately, we could say that Emotional Intelligence is almost of the same level for both Indians and Egyptians. Job Satisfaction is also of the same level between Egyptians and Indians. And for the Organizational Learning Capability, Indians get to learn more in their organizations having higher levels of OLC than Egyptians who score lower levels of OLC.

Discussing the relation between the variables themselves, we found that there is a non-significant relation between Emotional Intelligence and Job Satisfaction in both Egypt and India. This could be interpreted that no matter the level of Emotional Intelligence of Egyptians and Indians, this will not affect their satisfaction with their jobs. On the contrary for the relation between Job satisfaction and Organizational Learning Capability, there is a highly significant relation between both variables in Egypt and India and still stronger even in India. This could be interpreted by saying that Egyptians and Indians get more satisfied with their jobs when they learn more in their organizations. The derived results get support from the previous studies which found a positive association of job satisfaction with individual characteristics of the learning organization. Mikkelsen, Ogaard \& Lovrich identified a positive connection between learning climate and job satisfaction. A study done by Kellar et al., (1996) cited that there lies a positive relation between work climate and job satisfaction. Ahmad (2000) also found that workplace learning promoted a high level of job satisfaction among employees. Chiva \& Alegre (2008) declared that organizational learning ability through a stimulating work environment has effects in developing employees' competencies and job satisfaction. The reason for organizational learning capability to influence job satisfaction level could be that such an organization promotes a strong learning environment, team which makes the employees more satisfied with their jobs. For the relation between the Organizational Learning Capability and Emotional Intelligence; there is not a significant relation between OLC and EI in India. However, in Egypt, the case is different; there exists a highly significant relation between both variables (OLC and EI). This could be interpreted that for Indians it doesn't matter having high levels of Organizational learning when it comes to affecting their Emotional Intelligence. On the other hand; the more Egyptians get to learn in their organizations, the more the level of their Emotional Intelligence increases.

One last finding was done when dividing the Egyptian sample into two groups, one group with higher levels of OLC and the other group with lower levels of OLC. Making the analysis for both groups separately, it was found that the group with higher levels of OLC, the relation between EI and JS is positive and almost significant. On the other hand, the other group when having lower levels of OLC, the relation between EI and JS is inverse and non-significant. This could be explained that for Egyptians, the more that they have an opportunity for Organizational Learning, the more that the relationship between Emotional Intelligence and Job Satisfaction is strengthened for them. However, when 
trying to apply this case for India, it didn't show the same results. The Indian sample was also divided to two groups, one with lower levels of OLC and the other one with higher levels of OLC. The Analysis was also done for every group separately but the results in India show completely non-significant relations of EI-JS at both levels of OLC. However, a similar trend as for Egypt in that the relation is changed from being reverse at low OLC to positive in high OLC but both are still weak and non-significant. This could be interpreted by saying that, for Indians, no matter the level of OLC, high or low, this will not affect the relationship between Emotional Intelligence and Job Satisfaction by any means.

It is important to take into consideration that the study has limitations. First, it was administered among academicians only, in HEIs and not other staff members, which is considered to be a limitation as other stakeholders are not taken into account. Second, the study was conducted on private HEIs only, excluding the public institutions, which may limit external validity. It is recommended that further research should be done to test the hypotheses among public HEIs and including several stakeholders. Third, the sample size limits our conclusions to private HEIs in Egypt and India; the conclusions cannot be extended beyond this sector. Fourth, the study uses measurement scales to assess the variables in question; EI, OLC and JS, and measurement scales have limitations with regards to being subjective with regards to the responses, they tend to have both advantages and disadvantages (Fineman, 2004; Spector, 1992; Sharma, 1996; Hair et al., 1998). Fifth, since the study is of the comparative nature between two countries, it is important to note that although the surveys were substantively similar, there might have been some difference in the administration which may have changed the effect of EI on Job Satisfaction.

Finally, it is recommended for future research to go beyond the limitations, and investigate the relationship of the variables in question among other sectors, countries and cultures, as well as expanding the stakeholders involved. It is also recommended that future qualitative research would be conducted on participants who did not fit into the proposed relationships for EI, OLC and JS.

Some future recommendations would be to see the impact of gender, and age groups on the proposed variables; moreover, to see the impact of faculty EI and JS on student productivity and success, and to see the impact of culture and traditions on the variables in question.

\section{References}

Alam, M. M. (2009). The Relationships between the Emotional Intelligence and Job Satisfaction: Empirical Findings from Higher Education Institution in Malaysia. Journal of Management and Social Sciences, 5(2), 124-139.

Alegre, J., \& Chiva, R. (2008). Assessing the impact of organizational learning capability on product innovation performance: An empirical test. Technovation, 28(6), 315-326. http://dx.doi.org/10.1016/j.technovation.2007.09.003

Alegre, J., \& Chiva, R. (2008). Emotional intelligence and Job Satisfaction: the role of Organizational Learning Capability. Personnel Review, 37(6), 680-701. http://dx.doi.org/10.1108/00483480810906900

Ameli, F., Lari, M.A., \& Shooshtarian, Z. (2013). The Effect of Labor's Emotional Intelligence on Their Job Satisfaction, Job Performance and Commitment. Iranian Journal of Management Studies, 6(1), 27-43.

Arnold, J., \& Silvester, J. (2005). Work psychology: Understanding human behavior in the workplace. Pearson Education.

Cherniss C. (1998). Social and Emotional Learning for Leaders. Educational Leadership, 55(7), 26-28.

Chiva, R., \& Alegre, J. (2009). Organizational learning capability and job satisfaction: An empirical assessment in the ceramic tile industry. British Journal of Management, forthcoming. http://dx.doi.org/10.1111/j.1467-8551.2008.00586.x

Chiva, R., \& J. Alegre. (2008). Emotional intelligence and job satisfaction: the role of organizational learning capability. Personnel Review, 37(6), 680-701. http://dx.doi.org/10.1108/00483480810906900

Chiva, R., Alegre, J., \& Lapiedra, R. (2007). Measuring Organizational Learning Capability among the Workforce. International Journal of Manpower, 28(3/4), 224-242.

Dincer, H., \& Orhan, N. (2012). The Impacts of Emotional Intelligence Competency on Job Satisfaction in the Service Sector: An Application on the Turkish Banking Sector. Asian Economic and Financial Review, 2(5), 617-634.

Dodgson, M. (1993). Organizational Learning: A Review of Some Literatures. Organizational Studies, 14(3), 375-394. http://dx.doi.org/10.1177/017084069301400303 
Eylon, D., \& Bamberger, P. (2000). Empowerment cognitions and empowerment acts. Group \& Organization Management, 25(4), 354. http://dx.doi.org/10.1177/1059601100254003

Garvin, D. A., Edmondson, A. C., \& Gino, F. (2008). Is yours a learning organization? Harvard business review, 86(3), 109.

Goh, S., \& Richards, G. (1997). Benchmarking the learning capability of organizations, European Management Journal, 15(5), 575-83. http://dx.doi.org/10.1016/S0263-2373(97)00036-4

Griffin, M. A., Patterson, M. G., \& West, M. A. (2001). Job satisfaction and teamwork: the role of supervisor support. Journal of Organizational Behavior, 22(5), 537-550. http://dx.doi.org/10.1002/job.101

Huysman, M. (2000). An Organizational Learning Approach to the Learning Organization. European Journal of Work and Organizational Psychology, 9(2), 133-145. http://dx.doi.org/10.1080/135943200397905

Keller, R. T., Julian, S., \& Kedia, B. L. (1996). A multinational study of work climate, job satisfaction, and the productivity of R\&D teams. Engineering Management, IEEE Transactions on, 43(1), 48-55. http://dx.doi.org/10.1109/17.491268

Krishnakumar, S. (2008). The role of emotional Intelligence and job emotional requirements in job attitudes and behavior (Doctoral dissertation, Virginia Polytechnic Institute and State University).

Lund, D. (2003). Organizational culture and job satisfaction. Journal of Business \& Industrial Marketing, 18(3), 219-236. http://dx.doi.org/10.1108/0885862031047313

Malhotra, N. K., Kim, S. S., \& Patil, A. (2006). Common method variance in IS research: A comparison of alternative approaches and a reanalysis of past research. Management Science, 52(12), 1865-1883. http://dx.doi.org/10.1287/mnsc. 1060.0597

Martinez-Pons, M. (1997). The Relation of Emotional Intelligence with Selected Areas of Personal Functioning Imagination. Cognition and Personality, 17(1), 3-13. http://dx.doi.org/10.2190/68VD-DFXB-K5AW-PQAY

Mikkelsen, A., Ogaard, T., \& Lovrich, N. (2000). Modeling the Effects of Organizational Setting and Individual Coping Style on Employees Subjective Health, Job Satisfaction, and Commitment. Public Administration Quarterly, 24(3), 371-397.

Podsakoff, P. M., MacKenzie, S. B., Lee, J., \& Podsakoff, N.P. (2003). Common method biases in behavioral research: A critical review of the literature and recommended remedies. Journal of Applied Psychology, 88(5), 879-903. http://dx.doi.org/10.1037/0021-9010.88.5.879

Scott-Ladd, B., \& Chan, C. C. (2004). Emotional intelligence and participation in decision-making: strategies for promoting organizational learning and change. Strategic Change, 13(2), 95-105. http://dx.doi.org/10.1002/jsc.668

Senge, M. P., \& Sterman, J. D. (1990). System thinking and Organizational Learning: Acting Locally and thinking globally in the Organization of the Future. System Dynamics, 1007-1022.

Singh, S. K. (2007). Role of emotional intelligence in organizational learning: An empirical study. Singapore management review, 29(2), 55-74.

Srivastava, S. (2010). Moderating role of Emotional Intelligence on Stress-Effectiveness Relationship. The Journal of Innovation, 5(1), 89-98.

Srivastava, S. (2012). Work Place Passion as a Moderator for Workplace Deviant Behavior -Job Satisfaction Relationship: A Comparative study between Public Sector and Private Sector Managers. Asia Pacific Journal of Management Research \& Innovation, 8(4), 517-523.

Srivastava, S. (2013). Job Satisfaction and Organizational Commitment Relationship: Effect of Personality Variables. Vision-Journal of Business Perspective, 17(2) 21-30. http://dx.doi.org/10.1177/0972262912483529

Tsai, P. C. F., Yen, Y. F., Huang, L. C., \& Huang, I. C. (2007). A study on motivating employees' learning commitment in the post-downsizing era: Job satisfaction perspective. Journal of World Business, 42(2), 157-169. http://dx.doi.org/10.1016/j.jwb.2007.02.002 